\title{
Chronic total occlusions for intermediate volume operators: An antegrade step-up algorithm allows high success in easy and intermediate difficult CTO lesions
}

\author{
Joren Maeremans ${ }^{1}$, Philippe Selleslagh ${ }^{2}$, Luigi Di Serafino ${ }^{3}$, Emanuele Barbato $^{3}$, Joseph Dens $^{2}$ \\ ${ }^{1}$ Faculty of Medicine and Life Sciences, Hasselt University, Diepenbeek, Belgium \\ ${ }^{2}$ Department of Cardiology, Ziekenhuis Oost-Limburg, Genk, Belgium \\ ${ }^{3}$ Department of Cardiology, Onze-Lieve-Vrouw Ziekenhuis, Aalst, Belgium \\ Email: maeremansjoren@gmail.com
}

Received 17 October 2013; revised 21 November 2013; accepted 1 December 2013

Copyright (C) 2013 Joren Maeremans et al. This is an open access article distributed under the Creative Commons Attribution License, which permits unrestricted use, distribution, and reproduction in any medium, provided the original work is properly cited. In accordance of the Creative Commons Attribution License all Copyrights (C) 2013 are reserved for SCIRP and the owner of the intellectual property Joren Maeremans et al. All Copyright (C 2013 are guarded by law and by SCIRP as a guardian.

\begin{abstract}
To improve the success rates of chronic total occlusion (CTO) intervention, a large range of CTO-dedicated guidewires (GWs), devices and techniques have been developed. However, such an abundant choice of materials confuses inexperienced operators. Therefore, the usefulness of a simple antegrade treatment algorithm with a limited set of GWs, for easy to intermediate lesions, was investigated. Between November 2011 and March 2013, 105 patients were included, who underwent CTO PCI following the algorithm. Lesions were classified according to the Multicenter CTO Registry of Japan score. Overall technical success was achieved in $\mathbf{7 7 \%}$. Study endpoint was successful GW crossing within $30 \mathrm{~min}$ and was reached in $57 \%$. High success rates were achieved in easy $(81 \%)$ and intermediate $(64 \%)$ lesion types. In both types, a soft wire could successfully cross in $\mathbf{5 7 \%}$ and $\mathbf{5 1 \%}$ respectively, with the Fielder $\mathrm{XT}^{\circledR}$ (Asahi Intecc Co.) capable of crossing most commonly $(90 \%)$. The proposed treatment algorithm simplifies the percutaneous treatment of easy to intermediate CTO lesions. However, it merits further evaluation, especially for operators/centers who perform a low to intermediate amount of CTO PCI.
\end{abstract}

Keywords: Percutaneous Coronary Intervention; Chronic Total Occlusion; Interventional Cardiology; Coronary Angioplasty; Guidewires

\section{INTRODUCTION}

Currently, in $15 \%$ - $30 \%$ of all coronary angiograms performed in patients with single or multivessel coronary artery disease, at least one coronary chronic total occlusion (CTO) is present [1-3]. In non-randomized trials, successful recanalization of these CTOs has shown to improve survival, cardiac function and overall quality of life [2,4-7]. Nevertheless, $40 \%$ of these patients are treated medically or a large portion of these patients is referred for coronary artery bypass grafting (CABG) surgery, especially those with multivessel disease and a high syntax-score [3]. This reluctance to perform percutaneous coronary intervention (PCI) has historically been driven mainly by anatomical factors, related to the CTO. Because of these, several technical difficulties often arise during the interventional procedure, most commonly the crossing of the guidewire (GW) into the distal true lumen of the artery $[4,6]$.

A large range of CTO-dedicated GWs and devices have been developed to reduce treatment failure rates. However, such an abundant choice of GW types, all with specific characteristics (polymer-coated vs. non-coated; jacket vs. sleeve coatings; spring vs. non-spring coil; low vs. high tip load; ...) confuses the operator, being unable to build up sufficient experience with one type or set of wires, especially in low or intermediate PCI volume centers. Besides GWs, complex algorithms, including retrograde and hybrid approaches, have also been developed by experienced operators. Unfortunately, these complex techniques will not be applied by low or intermediate volume operators, resulting in reluctance to tackle the CTO lesion. Therefore, a simple step-up approach with the new generation of wires and microcatheters might result in reduced failure rates in easy CTO lesions and those with intermediate difficulty.

The present study investigated the usefulness of such a 
simple antegrade treatment algorithm with a limited set of GWs to treat CTOs, especially easy and intermediate difficult lesions. Having a pragmatic and structured approach to simpler lesions may also encourage less experienced operators to treat more CTOs via PCI with higher success rates. Procedural success was defined as successful GW crossing within 30 minutes, since GW crossing is often the limiting factor for general procedural success and because other factors such as operator's skill, experience, judgment and perseverance can influence general procedural outcome. CTOs were categorized according to the Multicenter CTO Registry of Japan (J-CTO) scoring criteria, developed by Morino et al. [8], to assess the success rates related to angiographic characteristics. The results of this study were compared with those of Fujino et al. and the European Registry of Chronic Total Occlusion (ERCTO) (Galassi et al.) $[9,10]$.

\section{METHODS}

\subsection{Study Population}

Between November 2011 and March 2013, a Belgian two-center, non-randomized, prospective registry was conducted in the hospitals of Genk (ZOL) and Aalst (OLVZ), with permission to collect data by the institutional research ethics boards. Patients included in the study have given informed consent to collect data. Both centers perform 1200 - 1500 PCIs and 40 to 70 CTO procedures a year. Different operators perform CTOprocedures, but the majority of these are executed by two operators (one in each center). CTO procedure data were collected prospectively in 108 consecutive patients. Patients were selected for CTO PCI based on their clinical symptoms, left ventricular viability and/or documented ischaemia. Baseline demographics, angiographic characteristics, procedural characteristics and outcomes were analyzed. For the purpose of the analysis, the data of those patients, in whom the applied algorithm (cfr. "step-up strategy") was followed, were used (105 patients). CTOs treated by the retrograde approach were excluded. CTOs were categorized according to the JCTO criteria [8]. Four groups were created, based on the difficulty of the CTO lesion (easy (0), intermediate (1), difficult (2) and very difficult $(\geq 3)$ ). The difficulty corresponds to the amount of negative angiographic characteristics of the CTO lesion ("blunt type at the entry site", "bending $\left(\geq 45^{\circ}\right)$ ", "calcification", "occlusion length $(\geq 20$ $\mathrm{mm})$ " and/or "previously failed lesion").

\subsection{Definitions}

A CTO was defined as a lesion of a native coronary artery which exhibited Thrombosis in Myocardial Infarction (TIMI) antegrade flow 0 and which was present for at least 3 months. Angiographic characteristics were de- fined as reported by Morino et al. [8]. To estimate the length of the occlusion, in these lesions with retrograde filling from the opposite artery, an angiogram performed by bilateral arterial approach and the length of the first PCI-balloon crossing the lesion was used. Occlusion length was then categorized as $<20$ or $\geq 20 \mathrm{~mm}$, as described by the EuroCTOClub [11].

As an endpoint for this study, GW manipulation time was used, as did Morino et al. [8]. This is the time from initial insertion of the GW into the coronary artery to the time of successful crossing or being pulled out because of failure. To categorize this numerical variable, a 30 minutes cutoff value was set as a threshold for successful GW crossing.

\subsection{Step-Up Strategy}

The antegrade step-up algorithm, which is mainly intended for easy to intermediate difficult lesions, is as follows (Figure 1, Table 1): unless the CTO-lesion is ostial or post-ostial, a microcatheter (Finecross ${ }^{\circledR}$ (Terumo Interventional Systems) or Corsair ${ }^{\circledR}$ (Asahi Intecc Co.)) is delivered over a soft wire (Figure 2). The soft wire is exchanged for a Fielder $\mathrm{XT}^{\circledR}$ or $\mathrm{FC}^{\circledR}$ (Asahi Intecc Co.) wire (Figure 3). This technique allows a

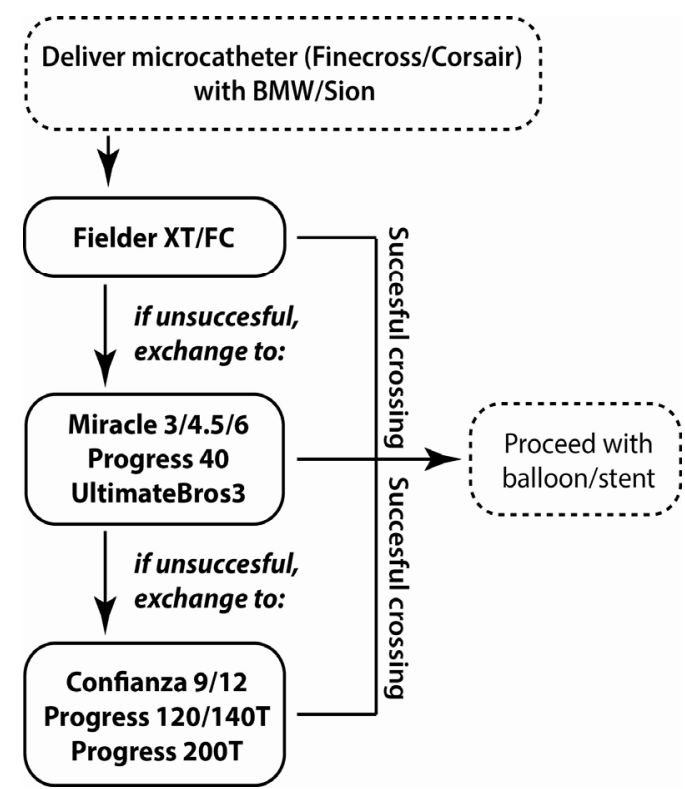

Figure 1. Algorithm for crossing chronic total occlusions.

Table 1. Overview of applied guidewires during PCI, based on guidewire tip load.

\begin{tabular}{ccc}
\hline $\begin{array}{c}\text { Soft wires } \\
(<\mathbf{3} \mathbf{~ g})\end{array}$ & $\begin{array}{c}\text { Intermediate stiff wires } \\
(\mathbf{3}-\mathbf{6} \mathbf{~ g})\end{array}$ & $\begin{array}{c}\text { Stiff wires } \\
(>\mathbf{6} \mathbf{~ g )}\end{array}$ \\
\hline Fielder $\mathrm{XT}^{*}$ & UltimateBros3 & Confianza \\
Fielder $\mathrm{FC}^{*}$ & $\begin{array}{c}\text { Miracle } 3,4.5,6^{*} \\
\text { Progress } 40^{* *}\end{array}$ & $\begin{array}{c}\text { Progress } 120 / 140 \mathrm{~T}^{* *} \\
\text { Progress 200T }\end{array}$ \\
\hline
\end{tabular}

${ }^{*}$ Asahi Intecc Co.; ${ }^{* *}$ Abbott Vascular. 


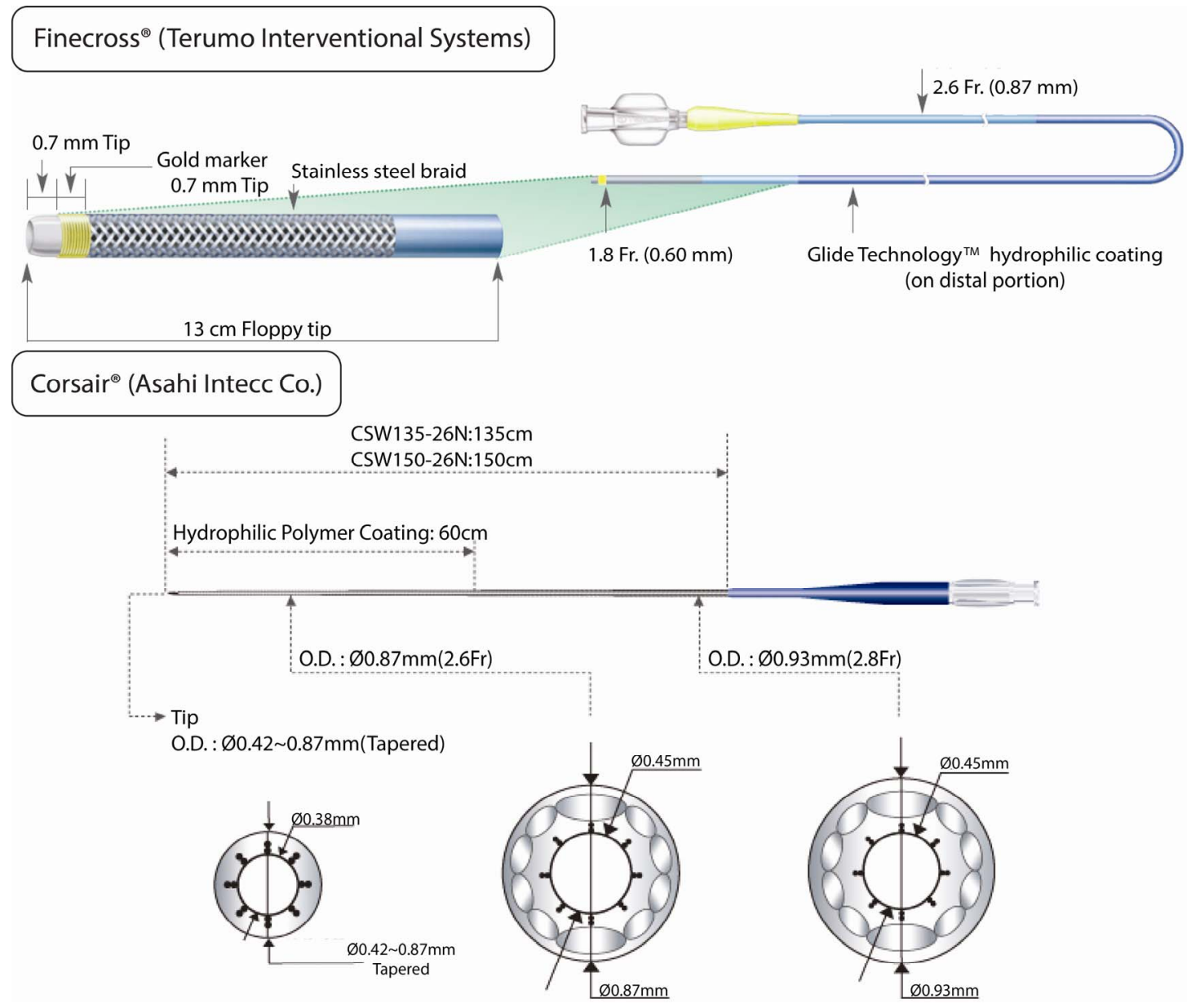

Figure 2. Structure of Finecross ${ }^{\circledR}$ (Terumo Interventional Systems) and Corsair ${ }^{\circledR}$ (Asahi Intecc Co.) microcatheters.

$$
\text { Fielder } \mathrm{XT}^{\oplus} \text { (Asahi Intecc Co.) }
$$

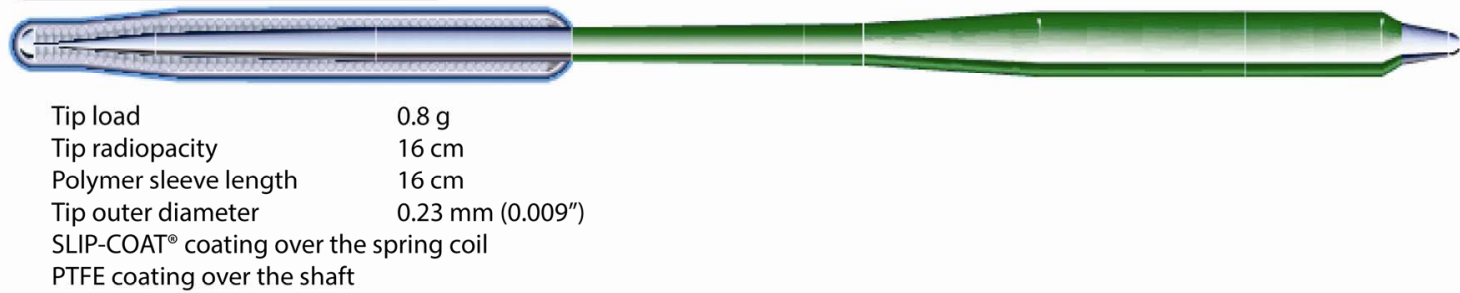

\section{Progress $40^{\circledR}$ (Abbott Vascular)}

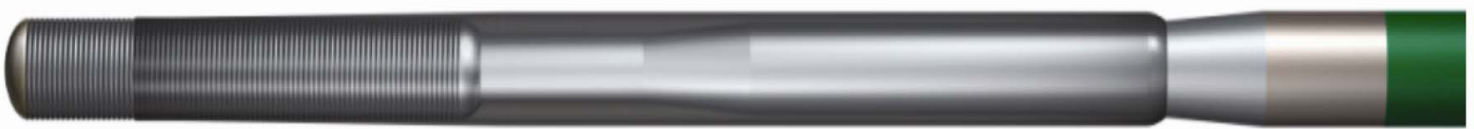

$\begin{array}{ll}\text { Tip Load } & 4.8 \mathrm{~g} \\ \text { Radiopaque length } & 3 \mathrm{~cm} \\ \text { Outside diameter } & 0.014^{\prime \prime} \\ \text { Tip outside diameter } & 0.012^{\prime \prime} \\ \text { Coating } & \text { Hydrophilic } \\ \text { Tip Style } & \text { Core to tip } \\ \text { Polymer Cover } & \text { Intermediate Polymer Sleeve } \\ \text { Core Material } & \text { DURASTEEL }\end{array}$

Figure 3. Structure of Fielder $\mathrm{XT}^{\circledR}$ (Asahi Intecc Co.) and Progress $40^{\circledR}$ (Abbott Vascular) guidewires. 
specific shape of the tip of the dedicated CTO wire. Fielder $\mathrm{XT}^{\circledR}$ and $\mathrm{FC}^{\circledR}$ are defined as soft wires, based on the low tip load of these wires. Upon failure, a GW exchange to an intermediate stiff wire was made. Following the algorithm, this second wire is a Miracle ${ }^{\circledR} 3 / 4.5 / 6$ (Asahi Intecc Co.) or Progress $40^{\circledR}$ (Abbott Vascular). During the registry, the UltimateBros $3^{\circledR}$ (Asahi Intecc Co.) became available which replaced the Miracle $^{\circledR}$ as the wire of preference. If unsuccessful, exchange towards even more stiff wires was performed, with the Confianza $^{\circledR}$ (Pro) (Asahi Intecc Co.), Progress ${ }^{\circledR}$ 120, 140T and 200T (Abbott Vascular) as preferred wires. In both centers the wire of preference to start with was the Fielder $\mathrm{XT}^{\mathbb{B}}$ wire.

\subsection{Guidewires}

The Fielder $\mathrm{XT}^{\circledR}$ is a soft and tapered GW with a tip load and diameter of respectively $0.8 \mathrm{~g}$ and 0.009 " (Figure 3). The outer diameter is $0.014 "$. It has a stainless steel spring coil core, with a hydrophilic polymer sleeve coating at the distal end of the wire which provides lubricity and trackability for tortuous vessels. A PTFE-coating covers the shaft of the wire. The Fielder $\mathrm{FC}^{\circledR}$ has similar characteristics as the Fielder $\mathrm{XT}^{\circledR}$ but is not tapered and its polymer sleeve is a bit longer. The Miracle ${ }^{\circledR} 3 / 4.5 / 6$ and UltimateBros $3^{\circledR}$ GWs are both intermediate stiff GWs with tip loads between 3 and $6 \mathrm{~g}$. The core wire and distal coil are designed to resist great force. The higher tip load increases driving force against tight lesions. The UltimateBros $3^{\circledR}$ has a longer hydrophilic polymer coating which maintains high maneuverability, allowing improved wire manipulation in tight lesions. The Confianza ${ }^{\circledR} \mathrm{GW}$ has a tapered tip diameter of $0.009 "$ and a non-hydrophilic coating. In combination with its heavy tip load, highly resistant lesions can be penetrated. The Progress ${ }^{\circledR}$-family is a family of CTO wires coated with a lubricious, hydrophilic sleeve coating (Figure 3). As a core, these wires have DURASTEEL ${ }^{\mathbb{B}}$ and both the outer and tip diameter is 0.014 ". This family has different tip loads resulting in a range of tip stiffness.

\subsection{Statistical Analysis}

Univariate analyses were performed to assess the relationship between the patients' baseline and angiographic characteristics and successful GW crossing within 30 minutes. Numerical values were expressed as mean \pm standard deviation, while categorical variables were expressed as percentage of total. Normality was assessed using the Shapiro-Wilk statistic. Comparisons between groups were performed using Fisher's exact test for categorical variables and the independent Student's t-test for continuous variables, with the level of significance set at $\mathrm{p} \leq 0.05$. Data on procedural characteristics and procedural success rates were also calculated for the different J-CTO difficulty groups. In addition, a subdivision was made according to the applied treatment algorithm. All statistical analyses were carried out using SPSS Statistics version 20 (IBM SPSS Inc.).

\section{RESULTS}

\subsection{Study Population, Overall Results and Procedural Characteristics}

The algorithm was followed in 105 out of 108 patients (97.2\%). In 81 of these patients, general success was achieved (77.1\%) (Table 2). Lesions were categorized into difficulty risk groups (easy, intermediate, difficult and very difficult), according to the J-CTO scoring model [8]. In this way, respectively $21,42,28$ and 14 patients were assigned to each group. In $83.8 \%$ of all lesions, a microcatheter was used. Overall success was achieved in $90.5 \%, 81 \%, 82.1 \%$ and $35.7 \%$ of each group respectively. For each risk group, procedural characteristics were evaluated (Table 2). This includes the number of wires used, procedure times, fluoroscopy times, contrast use and radiation doses. An increase in these values is seen in accordance with lesion difficulty. The values in the very difficult group do not differ significantly from the difficult, due to abortion of the procedure by the operator, if it seemed futile to continue. Nevertheless, these values are relatively low and clearly within safety margins for contrast use and radiation exposure.

The primary endpoint of this study was successful GW crossing within 30 minutes. The baseline characteristics as well as angiographic characteristics and procedural outcomes of the study population, classified according to this primary endpoint, are reported in Table 3. No significant differences were present between the two groups for baseline characteristics except for age $(62.9 \pm 10.9$ vs. $67.4 \pm 9.5, \mathrm{p}=0.03)$. Concerning angiographic characteristics, the failure rate to cross within 30 minutes was clearly higher if the shape of the entry site was blunt $(10.0 \%$ vs. $40.0 \%, \mathrm{p}=0.000)$ and when calcifications were present $(28.3 \%$ vs. $57.8 \%, p=0.003)$. Other angiographic characteristics were not significantly different, although this might be due to the sample size.

\subsection{Successful Guidewire Crossing and Step-Up Algorithm}

In $57 \%$ of all patients, the primary endpoint of successful GW crossing within 30 minutes was achieved (Table 4). According to the model of Morino et al. [8], the primary endpoint was achieved in 17 (81\%), 27 (64\%), $13(46 \%)$ and 3 (21\%) cases respectively.

In total, $43 \%$ of 94 CTO lesions could be crossed within 30 minutes by using only soft wires. In $95 \%$ of 
Table 2. Overall success and mean procedural characteristics according to J-CTO risk groups.

\begin{tabular}{cccccc}
\hline & Total & Easy & Intermediate & Difficult & Very difficult \\
\hline $\mathbf{N}^{\circ}$ of patients (n) & 105 & 21 & 42 & 28 & 14 \\
Overall success (n (\%)) & $81(77.1 \%)$ & $19(90.5 \%)$ & $34(81.0 \%)$ & $23(82.1 \%)$ & $5(35.7 \%)$ \\
Procedure time (min) & $90 \pm 50$ & $86 \pm 42$ & $85 \pm 49$ & $97 \pm 52$ & $97 \pm 60$ \\
Radiation dose (mGy) & $1949 \pm 876$ & $1328 \pm 602$ & $1979 \pm 958$ & $2132 \pm 786$ & $2214 \pm 815$ \\
$\quad$ Contrast (ml) & $304 \pm 128$ & $296 \pm 79$ & $307 \pm 110$ & $320 \pm 181$ & $279 \pm 120$ \\
Fluoroscopy time (min) & $31 \pm 24$ & $23 \pm 10$ & $29 \pm 17$ & $39 \pm 38$ & $32 \pm 14$ \\
$\mathbf{N}^{*}$ of wires used (n) & $3.54 \pm 1.77$ & $2.95 \pm 1.47$ & $3.40 \pm 1.64$ & $3.86 \pm 1.76$ & $4.21 \pm 2.29$ \\
\hline
\end{tabular}

Procedural values are expressed as mean $\pm \mathrm{SD} .{ }^{*} 2,37,3$ and 4 missing values were reported for procedure time, radiation dose, contrast and fluoroscopy time respectively.

Table 3. Baseline and angiographic characteristics, according to successful guidewire crossing within 30 minutes.

\begin{tabular}{|c|c|c|c|}
\hline Variable & Successful $(n=60)$ & Failure $(n=45)$ & p Value \\
\hline Age & $62.9 \pm 10.9$ & $67.4 \pm 9.5$ & 0.03 \\
\hline Male & $75.0 \%$ & $82.2 \%$ & 0.5 \\
\hline BMI $^{*}$ & $29.4 \pm 5.2$ & $28.5 \pm 4.2$ & 0.4 \\
\hline SBP & $136 \pm 26.7$ & $136 \pm 22.0$ & 1.0 \\
\hline DBP & $73.7 \pm 11.6$ & $72.1 \pm 11.9$ & 0.5 \\
\hline $\mathbf{E F}$ & $61.7 \pm 14.9$ & $62.7 \pm 10.6$ & 0.7 \\
\hline Current smoker & $38.3 \%$ & $28.9 \%$ & 0.5 \\
\hline Hypertension & $53.3 \%$ & $53.3 \%$ & 1.0 \\
\hline Dyslipidemia & $78.3 \%$ & $64.4 \%$ & 0.13 \\
\hline Diabetes & $28.3 \%$ & $28.9 \%$ & 1.0 \\
\hline Prior MI & $26.7 \%$ & $24.4 \%$ & 0.8 \\
\hline Prior PCI & $33.3 \%$ & $37.8 \%$ & 0.7 \\
\hline Prior CABG & $15.0 \%$ & $15.6 \%$ & 1.0 \\
\hline Prior PVD & $28.3 \%$ & $28.9 \%$ & 1.0 \\
\hline Prior CVD* & $9.3 \%$ & $7.0 \%$ & 1.0 \\
\hline MVD & $50.0 \%$ & $53.3 \%$ & 0.8 \\
\hline $\begin{array}{c}\text { Target lesion } R C A \\
L A D \\
C X\end{array}$ & $\begin{array}{l}53.3 \% \\
23.3 \% \\
23.3 \%\end{array}$ & $\begin{array}{l}42.2 \% \\
44.4 \% \\
13.3 \%\end{array}$ & 0.06 \\
\hline \multicolumn{4}{|c|}{$\%$ Presence of negative characteristics/lesion } \\
\hline Previously failed lesion & $8.3 \%$ & $13.3 \%$ & 0.5 \\
\hline $\begin{array}{l}\text { Blunt stump type } \\
\quad \text { at entry }\end{array}$ & $10.0 \%$ & $40.0 \%$ & 0.000 \\
\hline Bending $>45^{\circ}$ & $13.3 \%$ & $15.6 \%$ & 0.8 \\
\hline Calcification & $28.3 \%$ & $57.8 \%$ & 0.003 \\
\hline $\begin{array}{c}\text { Occlusion length } \geq 20 \\
\mathrm{~mm}\end{array}$ & $43.3 \%$ & $51.1 \%$ & 0.4 \\
\hline Bridging collaterals & $31.7 \%$ & $15.6 \%$ & 0.07 \\
\hline $\begin{array}{l}\text { Side-branch }<5 \mathrm{~mm} \\
\text { from prox. cap }\end{array}$ & $61.7 \%$ & $71.1 \%$ & 0.4 \\
\hline $\begin{array}{c}\text { Rentrop class } \\
(\text { grade }=3)\end{array}$ & $51.7 \%$ & $55.6 \%$ & 0.9 \\
\hline
\end{tabular}

Values are expressed as $\%$ or mean $\pm \mathrm{SD}$. ${ }^{*} 12$ and 8 missing values were reported for $\mathrm{BMI}$ and $\mathrm{CVD}$ respectively. $\mathrm{BMI}=$ body mass index; $\mathrm{CABG}=$ coronary artery bypass grafting; $\mathrm{CVD}=$ cerebrovascular disease (CVA/TIA); $\mathrm{CX}=$ circumflex artery; $\mathrm{DBP}=$ mean diastolic blood pressure $; \mathrm{EF}=$ ejection fraction; $\mathrm{LAD}=$ left anterior descending artery; $\mathrm{MI}=$ myocardial infarction; MVD = multivessel disease; PCI = percutaneous coronary intervention; $\mathrm{PVD}=$ peripheral vascular disease; $\mathrm{RCA}=$ right coronary artery; $\mathrm{SBP}=$ mean systolic blood pressure. these cases, the Fielder $\mathrm{XT}^{\circledR}$ (Asahi Intecc Co.) was capable of crossing the lesion. According to lesion difficulty, the success rate with a soft wire was $57 \%(12 / 21$ lesions) for the easy group and 51\% (20/39) for the intermediate lesions. A Fielder $\mathrm{XT}^{\circledR}$ was capable of crossing in $92 \%$ and $95 \%$ of these groups respectively. For the difficult and very difficult groups, the success rate with only a soft wire was $24 \%(5 / 21)$ and $23 \%(3 / 13)$ respectively. Following the step-up strategy, lesions which failed to be crossed with a soft wire were attempted by an intermediate wire and/or stiff wire. However, not in all the lesions additional wire escalation was performed, due to sub-intimal dissection and/or in the operator's judgement further attempts would be futile. The number of wires used and the additional success rates with these wires are presented in Table 4.

In the data presented here, only 2 non-ST segment elevation myocardial infarctions (non-STEMI) occurred in the hospital of Genk. Besides this, no death, Q-wave myocardial infarction (MI) or pericardial effusion needing drainage occurred during the procedures.

\section{DISCUSSION}

To date, several papers address the use of different CTO devices and techniques. They represent the results of operators who are highly experienced in CTOs, performing more than $100 \mathrm{CTO}$ procedures/year. Often they report on high success rates in both easy and difficult lesions, using different guidewires, devices and complex techniques, including retrograde and hybrid approaches $[12,13]$. However, in general more CTO procedures are still performed by less experienced operators, for whom these techniques are not directly applicable, especially in low or intermediate volume centers. Therefore, a simple antegrade step-up algorithm for easy and intermediate difficult CTOs still is worthwhile to be adapted.

This was investigated in a prospective study of 105 consecutive CTO procedures, performed in two intermediate volume CTO centers. The algorithm is based on the development of second generation dedicated CTO-wires (Fielder $^{\circledR}$, Miracle ${ }^{\circledR}$, UltimateBros ${ }^{\circledR}$, Confianza ${ }^{\circledR}$ (Asahi 
Table 4. Successful guidewire crossing within 30 minutes, according to J-CTO difficulty groups and applied step-up strategy.

\begin{tabular}{cccccc}
\hline & Total & Easy & Intermediate & Difficult & Very difficult \\
\hline $\mathbf{N}^{\circ}$ of patients $(\mathbf{n})$ & 105 & 21 & 42 & 28 & 14 \\
Successful crossing $\leq \mathbf{3 0}$ minutes & $57 \%(60 / 105)$ & $81 \%(17 / 21)$ & $64 \%(27 / 42)$ & $46 \%(13 / 28)$ & $21 \%(3 / 14)$ \\
Success with soft wires & $43 \%\left(40 / 94^{\varepsilon}\right)$ & $57 \%(12 / 21)$ & $51 \%\left(20 / 39^{*}\right)$ & $24 \%\left(5 / 21^{\Delta}\right)$ & $23 \%\left(3 / 13^{\gamma}\right)$ \\
Additional success with intermediate wires & $37 \%(15 / 41)$ & $60 \%(3 / 5)$ & $54 \%(7 / 13)$ & $33 \%(5 / 15)$ & $0 \%(0 / 8)$ \\
Additional success with stiff wires & $19 \%(5 / 27)$ & $66 \%(2 / 3)$ & $0 \%(0 / 7)$ & $17 \%(3 / 10)$ & $0 \%(0 / 7)$ \\
\hline
\end{tabular}

${ }^{*} 3 / 42$ lesions were treated immediately with an intermediate stiff wire; ${ }^{\Delta} 7 / 28$ lesions were treated immediately with an intermediate stiff wire; ${ }^{\gamma} 1 / 14$ lesions was treated with immediately with a stiff wire; ${ }^{\varepsilon}$ In total 11 lesions were not treated with a soft wire.

Intecc Co.) and the Progress ${ }^{\circledR}$-family (Abbott Vascular)), allowing operators to get familiar with a limited set of wires. With the use of this set of dedicated CTO-wires and the routine use of a microcatheter, this algorithm should simplify procedures.

In this study, GW manipulation time was used as the endpoint for success [8]. This was done because successful GW crossing is most often the limiting factor for general procedural success. Consequently, the J-CTO scoring model was used to categorize the lesions according to difficulty [8]. The overall success rate with the applied algorithm was $77.1 \%$, while it was possible to cross the lesion within 30 minutes in 57\%. For each risk group, similar success rates are achieved for this primary endpoint $(81 \%, 64 \%, 46 \%$ and $21 \%$ respectively), compared to those of Morino et al. (derivation set: $87.7 \%$, $67.1 \%, 42.4 \%, 10 \%$ and validation set: $92.3 \%, 58.3 \%$, $34.8 \%, 22.2 \%$ respectively) [8]. We routinely used a microcatheter as back-up to increase wire tip load and support. These results confirm that the technique works well in easy to intermediate type of CTO lesions and that for more difficult lesions, one needs different materials, techniques and experience to be successful.

In $43 \%$ of all cases, soft wires were able to cross the lesion within 30 minutes, $95 \%$ of these lesions were crossed with the Fielder $\mathrm{XT}^{\circledR}$. Moreover, when looking at the "easy" and "intermediate" lesions, a success rate of up to $57 \%$ and $51 \%$ was achieved, with the Fielder $\mathrm{XT}^{\circledR}$ capable of crossing in $92.5 \%$ and $95 \%$ of the cases respectively. This result is similar to the findings of Fujino et al. [10]. They reported a success rate of $37 \%$ for patients treated only with a single soft wire (Fielder $\mathrm{XT}^{\circledR} / \mathrm{XT}-\mathrm{R}^{\circledR}$ ). However, general success in all types of lesions was used as endpoint in this study. Besides this, Galassi et al. reported a slightly lower success rate ( $29.2 \%$ vs. $43 \%$ ). $36 \%$ of these were successfully crossed with a Fielder $\mathrm{XT}^{\circledR}$, which is clearly lower than in our study, due to different lesion selection [9].

\section{CONCLUSION}

From the results of this study, using a step-up algorithm, in which a pre-defined set of new generation CTOdedicated wires is used, high success rates in easy and intermediate type of lesions can be obtained. In particular the use of a Fielder $\mathrm{XT}^{\circledR}$ as a wire of first choice simplifies the procedure. The additional benefit is the overall limited number of wires, fluoroscopy, contrast, procedure time and radiation, reducing costs and increasing safety. We therefore strongly encourage less experienced and intermediate volume operators/centers to follow a treatment algorithm, in which a select set of CTOdedicated guidewires is used, to get familiar with. The presented algorithm can serve as a guideline for this, especially in the case of so called easy CTOs and those of intermediate difficulty. For more difficult lesions (i.e. J-CTO score of 3), which are less easy to deal with, an onward referral to an expert CTO center should be considered.

\section{REFERENCES}

[1] Arslan, U., Balcioglu, A.S., Timurkaynak, T. and Cengel, A. (2006) The clinical outcomes of percutaneous coronary intervention in chronic total coronary occlusion. International Heart Journal, 47, 811-819.

[2] Godino, C., Bassanelli, G., Economou, F.I., Takagi, K., Ancona, M., Galaverna, S., et al. (2013) Predictors of cardiac death in patients with coronary chronic total occlusion not revascularized by PCI. International Journal of Cardiology, 168, 1402-1409. http://dx.doi.org/10.1016/j.ijcard.2012.12.044

[3] Fefer, P., Knudtson, M.L., Cheema, A.N., Galbraith, P.D., Osherov, A.B., Yalonetsky, S., et al. (2012) Current perspectives on coronary chronic total occlusions: The Canadian Multicenter Chronic Total Occlusions Registry. Journal of the American College of Cardiology, 59, 991997. http://dx.doi.org/10.1016/j.jacc.2011.12.007

[4] Rathore, S., Katoh, O., Matsuo, H., Terashima, M., Tanaka, N., Kinoshita, Y., et al. (2009) Retrograde percutaneous recanalization of chronic total occlusion of the coronary arteries: Procedural outcomes and predictors of success in contemporary practice. Circulation: Cardiovascular Interventions, 2, 124-132. http://dx.doi.org/10.1161/CIRCINTERVENTIONS.108.8 38862

[5] Borgia, F., Viceconte, N., Ali, O., Stuart-Buttle, C., Saraswathyamma, A., Parisi, R., et al. (2012) Improved cardiac survival, freedom from MACE and angina-related 
quality of life after successful percutaneous recanalization of coronary artery chronic total occlusions. International Journal of Cardiology, 161, 31-38. http://dx.doi.org/10.1016/j.ijcard.2011.04.023

[6] Suero, J.A., Marso, S.P., Jones, P.G., Laster, S.B., Huber, K.C., Giorgi, L.V., et al. (2001) Procedural outcomes and long-term survival among patients undergoing percutaneous coronary intervention of a chronic total occlusion in native coronary arteries: A 20 -year experience. Journal of the American College of Cardiology, 38, 409-414.

[7] Khan, M.F., Wendel, C.S., Thai, H.M. and Movahed, M.R. (2013) Effects of percutaneous revascularization of chronic total occlusions on clinical outcomes: A metaanalysis comparing successful versus failed percutaneous intervention for chronic total occlusion. Catheterization and Cardiovascular Interventions, 82, 95-107. http://dx.doi.org/10.1002/ccd.24863

[8] Morino, Y., Abe, M., Morimoto, T., Kimura, T., Hayashi, Y., Muramatsu, T., et al. (2011) Predicting successful guidewire crossing through chronic total occlusion of native coronary lesions within 30 minutes: The J-CTO (Multicenter CTO Registry in Japan) score as a difficulty grading and time assessment tool. JACC: Cardiovascular interventions, 4, 213-221. http://dx.doi.org/10.1016/j.jcin.2010.09.024

[9] Galassi, A., Tomasello, S., Reifart, N., Werner, G., Sianos, G., Bonnier, H., et al. (2011) In-hospital outcomes of percutaneous coronary intervention in patients with chronic total occlusion: insights from the ERCTO (European Registry of Chronic Total Occlusion) registry. Eurointervention, 7, 472-479.

http://dx.doi.org/10.4244/EIJV7I4A77

[10] Fujino, A., Sakamoto, H., Fujino, M., Yamane, T., Adachi, T., Jinnai, T., et al. (2012) The procedural benefit of soft and tapered tip guidewire use as a first choice for chronic total occlusion revascularisation. Journal of the American College of Cardiology, 59, E106. http://dx.doi.org/10.1016/S0735-1097(12)60107-7

[11] Di Mario, C., Werner, G.S., Sianos, G., Galassi, A.R., Buttner, J., Dudek, D., et al. (2007) European perspective in the recanalisation of Chronic Total Occlusions (CTO): Consensus document from the EuroCTO Club. EuroIntervention, 3, 30-43.

[12] Brilakis, E.S., Grantham, J.A., Rinfret, S., Wyman, R.M., Burke, M.N., Karmpaliotis, D., et al. (2012) A percutaneous treatment algorithm for crossing coronary chronic total occlusions. JACC: Cardiovascular Interventions, 5, 367-379. http://dx.doi.org/10.1016/j.jcin.2012.02.006

[13] Brilakis, E.S., Grantham, J.A., Thompson, C.A., DeMartini, T.J., Prasad, A., Sandhu, G.S., et al. (2012) The retrograde approach to coronary artery chronic total occlusions. Catheterization and Cardiovascular Interventions, 79, 3-19. http://dx.doi.org/10.1002/ccd.23004 